\title{
Qualitative study of women's anxiety and information needs after a diagnosis of cervical dysplasia
}

\author{
Gitte Lee Mortensen • Anny Lisbeth Adeler
}

Received: 17 December 2009 / Accepted: 18 March 2010/Published online: 31 March 2010

(C) The Author(s) 2010. This article is published with open access at Springerlink.com

\begin{abstract}
Aim Each year almost 15,000 Danish women are diagnosed with cervical dysplasia, a precursor to cervical cancer. The period of medical follow-up, or 'watchful waiting', to monitor for regression or progression of the lesion before deciding if treatment by conisation is necessary can be long. The aim of this study was to examine the experiences of women with different stages of cervical dysplasia and to examine whether their knowledge of human papillomavirus (HPV) as the cause of cervical dysplasia influenced their perception of their disease.

Subject and methods We used focus group and individual interviews with 12 women diagnosed with different stages of cervical dysplasia - women who had and had not been conised. Interview guides were prepared on the basis of a literature review that identified important issues and questions for the participants.

Results The participants considered cervical dysplasia to be a highly distressing condition and experienced monitoring as a worrying delay before regression of the lesions or treatment could be initiated. Women expressed a fear of cancer that was not proportional to the stage of their dysplasia, but was determined by their degree of knowledge about their condition. Unlike other sexually transmitted
\end{abstract}

The results of this study have been published previously in Ugeskrift for loeger, a Danish medical journal (Mortensen and Adeler 2009).

G. Lee Mortensen $(\bowtie)$

AnthroConsult,

Fynsgade 24, 2.t.h.,

8000 Aarhus C, Denmark

e-mail: glm@anthroconsult.dk

\section{A. L. Adeler}

Valdemarsgade Medical Clinic,

Aarhus, Denmark

e-mail: anny@adeler.dk diseases, information about HPV did not result in stigmatisation as the perception of this disease was dominated by cancer.

Conclusion This study showed that it is extremely important to address women's fears, their need for information and to ensure better communication with medical practitioners about cervical dysplasia immediately after diagnosis, irrespective of the disease stage.

Keywords Cervical dysplasia $\cdot$ Human papillomavirus . Disease perception

\section{Introduction}

Cervical dysplasia, the abnormal growth of cells of the uterine cervix (also known as cervical intraepithelial neoplasia or $\mathrm{CIN}$ ), is a precancerous lesion. It is estimated that $90 \%$ of these lesions regress spontaneously while the others progress into a more severe lesion and possibly cancer. Persistent infection with human papillomavirus (HPV) is a necessary cause of cervical dysplasia (Bosch and Lorincz 2002; Trottier and Franco 2006; Smith et al. 2007). Cervical dysplasia can be detected at an early stage by the Papanicolaou (Pap) cytological smear test. It can then be monitored regularly for regression of the lesion, or progression, before deciding if treatment by conisation is necessary (Bjerregaard 2007; National Board of Health 2007a). The introduction of cervical screening programmes based on the Pap smear has resulted in significant reductions in the incidence of cervical cancer, although some 37,000 women in Europe still die from this disease each year (Engholm et al. 2008).

Cervical cancer is the second most common cancer in women worldwide. In Europe the incidence was estimated 
to be 33,441 in 2002 (Ferlay et al. 2004). In Denmark, which has a population of about 5 million, the lifetime risk of developing cervical cancer is $1 \%$, and every year approximately 400 new cases of cervical cancer are diagnosed and about 175 women die from the disease (Clemmensen et al. 2006; National Board of Health 2007b). Since the introduction of organised cervical screening for women aged 23-60 years in Denmark in the 1960s, there has been a $50 \%$ decrease in the prevalence of cervical cancer, but the incidence of cervical cancer remains one of the highest in the European Union (Engholm et al. 2008; Clemmensen et al. 2006).

Each year, approximately 14,800 Danish women receive a Pap smear result that indicates a cervical lesion or abnormality of varying degrees of severity (Fig. 1) (Clemmensen et al. 2006). The follow-up and clinical management of these women depends on the specific cytological changes identified, which are classified according to the Bethesda system (National Board of Health 2007a) and explained to the patient as "mild", "moderate" or "severe" cell changes (Fig. 1). In the case of mild changes, including atypical squamous cells of undetermined significance (ASCUS), atypical glandular cells (AGC) or low-grade squamous intraepithelial lesions (LSIL), the patient is monitored by Pap test every 6 months to 1 year to determine whether the dysplasia regresses or progresses. Women with moderate changes, such as atypical squamous cells, cannot exclude high-grade squamous intraepithelial lesion (HSIL) (ASC-H), HSIL or severe changes, including adenocarcinoma in situ (AIS), are referred to a private or hospital-based gynaecologist who examines the cervix by colposcopy and performs a biopsy. Some women with moderate changes (HSIL) may be managed by 'watchful waiting', which involves monitoring by colposcopy every 3 months, and they will be treated only if the lesion is seen to progress. Cases of severe dysplasia and cancer in situ are managed by conisation

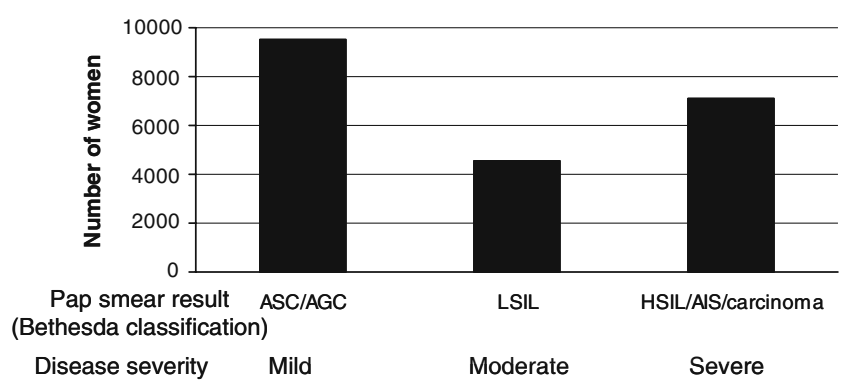

Fig. 1 Distribution of abnormal Pap smear results in Danish pathology departments in 2006 according to the Bethesda classification 2006 (National Board of Health 2007b). ASC atypical squamous cells, $A G C$ atypical glandular cells, LSIL low-grade squamous intraepithelial lesions, HSIL high-grade squamous intraepithelial lesion, AIS adenocarcinoma in situ (conical section or cone biopsy), which is the surgical removal (under sedation or general anaesthetic) of a coneshaped sample of cervical tissue. This is used as a diagnostic tool as well as treatment, if the histological analysis of the sample shows that all the abnormal tissue has been successfully removed. In Denmark, approximately 1 in 3 women $(5,000)$ with an abnormal Pap result undergo conisation each year (National Board of Health 2007a; Danish Gynaecological Cancer 2007; Bro et al. 2008). Currently, HPV testing in the setting of cervical cancer screening is not routinely performed in Denmark.

The period of watchful waiting between diagnosis of a lesion and confirmation of regression or need for treatment may last for several years and can be associated with a considerable psychological burden, as suggested by a number of studies in the literature (Lauver et al. 1999; French et al. 2004, 2006; Lerman et al. 1991; Ideström et al. 2003; Neale et al. 2003; Campion et al. 1988; McCaffery et al. 2004; Fleurence et al. 2007; Hounsgaard 2004; Waller et al. 2005; McCaffery et al. 2006). Overall, the results of these mainly quantitative studies show that women diagnosed with cervical dysplasia worried about the development of cancer. They often fear death and suffer from anxiety, stress and depression associated with worries about their sex life, fertility, medical supervision and potential interventions. The results show that women's lack of knowledge and poor doctor-patient communication can contribute to their anxiety (Lauver et al. 1999; French et al. 2004, 2006; Lerman et al. 1991; Ideström et al. 2003; Neale et al. 2003; Campion et al. 1988; McCaffery et al. 2004; Fleurence et al. 2007; Hounsgaard 2004). Women's knowledge about HPV is generally poor (Waller et al. 2005; McCaffery et al. 2006), but providing women with information about HPV and its role in cervical dysplasia has been shown to have both positive and negative effects. On the one hand, a better understanding has been reported to have a negative influence on women's perception of their condition, causing them to perceive it as a stigmatising sexually transmitted disease and producing feelings of shame, guilt and low self-esteem (Goffman 1968). Information about the high prevalence of HPV has, on the other hand, been reported to improve health-related behaviour (e.g. attendance at organised screening, use of condoms) (Waller et al. 2005, 2007; McCaffery et al. 2006; Kahn et al. 2005, 2007; Maissi et al. 2004; Clarke et al. 1996; McCree and Dempsey 2005).

The aim of this qualitative study, the first of its kind in a Danish context, was to examine the experiences of young women aged 25-35 years diagnosed with cervical dysplasia. In particular we looked at the ways in which they had been affected by the diagnosis and subsequent follow-up and treatment. We focused on the women's own understanding of the stage of their disease and its course, 
distinguishing between women who had undergone conisation and those who had not. We also sought to determine whether knowledge about HPV affected the women's perceptions of their disease. Patients' perceptions of a disease are known to be related to their socio-cultural context and these perceptions can influence the way in which they cope with the disease (Bishop 1991; Kleinman 1988; Hahn 1984).

\section{Methods}

Qualitative research methods can provide insights into the qualities of a phenomenon and the meanings that patients ascribe to it. The results can be generalised analytically, though not statistically (Malterud 2004), and can give a detailed understanding of the patients' perceptions of their illness. We used focus group and individual interviews to obtain as broad a range of perspectives on cervical dysplasia as possible. Focus groups were chosen to create a confidential environment in which women could openly discuss their experiences with cervical dysplasia, allowing us to gain insights into the social construction of meaning and the perception of this disease among women who had or had not undergone conisation, while individual interviews provided additional in-depth narratives about personal experiences with cervical dysplasia (Berger and Luckmann 1987; Halkier 2003; Bech Risør et al. 2005; Kvale 1996; Spradley 1979).

\section{Recruitment of study participants}

The participants were recruited from the practices of three private general practitioners (GPs) and two gynaecologists in the cities of Aarhus and Aalborg, Denmark, and from the gynaecology and obstetrics outpatient ward at Skejby Hospital, Aarhus, Denmark. Women aged between 25 and 35 years, who did not have any serious co-morbidity and who had either been diagnosed with cervical dysplasia within the past 3 months or had had a conical section within the past 6 months were eligible for inclusion. This age range was selected because of the high prevalence of cervical dysplasia. We did not seek the official diagnosis for the specific stage of cervical dysplasia for the women from their medical records since what was important was the women's own understanding of their stage (mild, moderate or severe dysplasia) and whether they had or had not been conised. We selected more women who had undergone conisation because they would have a longer experience of living with their condition and would be able to talk about how they felt before and after the conisation. Women were invited to participate in either an individual interview or in a focus group. We had individual interviews with one woman who had not undergone conisation and one who had (Table 1). Focus groups were organised with people of similar age to improve comparability of results and to facilitate honest and open group discussions. Also, since the topic was considered to be personal and potentially sensitive, we decided it was important that the focus groups included only a few participants. If the groups are too big

Table 1 Brief description of women included in focus groups or individual interviews

\begin{tabular}{ll}
$\begin{array}{l}\text { Woman's } \\
\text { number }\end{array}$ & Brief description \\
\hline $\begin{array}{l}\text { Individual interview } \\
1\end{array}$ & Woman who had not undergone conisation: \\
& abnormal smear test result 3 years before the \\
interview, declared free of cervical dysplasia & \\
& 2 weeks before the interview \\
5 & Woman who had undergone conisation: monitored \\
& for 8 months before conisation and 3-month \\
& follow-up results after conisation not received
\end{tabular}

Focus group 1: women who had not undergone conisation

Abnormal smear test result 8 weeks before the
interview, referred for colposcopy
Abnormal smear test result 14 weeks before the
interview, waiting for cytology result
Abnormal smear test result 4 weeks before the
interview, referred directly for conisation

Focus group 2: women who had undergone conisation

6 Referred directly for colposcopy and conisation after initial abnormal smear test result; 3-month follow-up results after conisation showed no dysplasia; 6-month follow-up results not received

$7 \quad$ Referred directly for colposcopy and conisation after initial abnormal smear test result; 3-month follow-up results after conisation showed no dysplasia; 6-month follow-up results not received

$8 \quad$ Monitored for 24 months before conisation; 3-month follow-up results after conisation showed no dysplasia; 6-month follow-up results not received

Focus group 3: women who had undergone conisation

9 Monitored for 18 months before conisation; 3-month follow-up results after conisation showed no dysplasia; 6-month follow-up results not received

10 Monitored for 12 months before conisation; 3-month follow-up results after conisation showed no dysplasia; 6-month follow-up results not received

11

Monitored for 60 months before conisation; 3-month follow-up results after conisation showed no dysplasia; 6-month follow-up results not received

Monitored for 3 months before conisation; 3-month follow-up results after conisation showed no dysplasia; 6-month follow-up results not received 
one or two participants could dominate the discussion or the participants can feel less comfortable talking about sensitive issues (Halkier 2003).

Women who fulfilled the inclusion criteria were informed orally about the study by the consulting physician who also gave them a study information sheet. We gave the physicians an instruction sheet describing how to present the study to their patients, underlining that the purpose of the study was to gain in-depth knowledge about the women's disease experiences and that no preparation or prior knowledge about cervical dysplasia were required in order to participate. Patients wishing to participate then contacted GLM, who was an independent researcher. Anonymity and confidentiality were ensured throughout the study. All women gave their informed consent to participate and the study did not require Ethics Committee approval.

Focus group and individual interviews

Semi- and funnel-structured interview guides were used to moderate the focus groups and structure the individual interviews. The topics and questions in the interview guides were selected on the basis of a literature review carried out before the start of the study. The questions were openended to capture as much information as possible, including any that had not been envisaged by pre-interview hypotheses (Halkier 2003; Kvale 1996). Individual interview guides were designed to produce an in-depth personal narrative of disease experience, while the focus group guides were designed to facilitate discussion. The guide used for focus group interviews with women who had undergone conisation is given in Table 2 as an example.

The first focus group was held after working hours in a staff meeting room at Skejby Hospital. Although this location was chosen as a neutral but familiar environment, the participants appeared to be uncomfortable in this setting and subsequent focus groups and interviews were held in small meeting rooms in hotels in Aalborg and Aarhus.

The focus group interviews were moderated by GLM with assistance from a colleague. The individual interviews were conducted by GLM only. The purpose and design of the study was explained at the beginning of each interview. It was emphasised that there were no wrong or right answers to the questions posed and that the aim was to obtain a realistic picture of all the participants' experiences and thoughts on having cervical dysplasia.

The interviews were transcribed verbatim and analysed using a discourse theoretical approach to the relationship between language and the social construction of meaning (Winther Jørgensen and Phillips 1999). The women's statements were seen as an expression as well as an ongoing construction of the meaning and personal impact of having cervical dysplasia. This approach is used to analyse a diversity of statements such that clusters of meaning are generated and involves an analysis of the terminology used to speak about the subject and the ways in which it is related to other issues. Firstly, the data were coded into the topics that were raised during the discussions. Secondly, the most important themes within each topic were identified. Finally, the frequency of and connections between topics and themes were analysed. This generated a pattern of the relative meaning that the different topics and themes had for the participants, i.e. the women's most significant experiences associated with having cervical dysplasia. All methodological and analytical steps were discussed and alternative interpretations sought with the authors and with an additional anthropologist. Disagreements were solved using Spradley's analytical process of resolution of qualitative data (Spradley 1979).

\section{Results}

In qualitative research, the validity of the results relies more on data collection until no significant new knowledge can be generated from it than the number of participants (Malterud 2004; Kvale 1996; Spradley 1979). In the present study, this point appeared to be reached after interviews had been conducted with a total of 12 women.

The characteristics of the women who participated are summarised in Table 1. Of the four participants who had not undergone conisation, three women had received their first abnormal smear test result in the 3 months before the interview. At the time of the study, one of these women had been referred for conisation and two were still waiting for the cytology results. One other woman had recently been declared free from cervical dysplasia after 3 years of monitoring. Eight participants had undergone conisation in the 6 months before the interview. Most of these women had received the results of the 3-month post-conisation check-up, but none had yet received the results of the 6month check-up. Three of these women had been referred directly for colposcopy and conisation after receiving the initial abnormal smear test result. The remaining five women had been monitored for $1-5$ years before being referred for conisation.

Two focus groups were held with women who had undergone conisation, one group with three participants and one with four participants. An individual interview was conducted with the remaining woman who had undergone conisation. One focus group was held with three women who had not undergone conisation; one individual interview was held with a woman who had not undergone conisation. 
Table 2 Example of interview guide used for focus groups: women who had undergone a cone biopsy

\begin{tabular}{|c|c|c|}
\hline $\begin{array}{l}\text { Interview } \\
\text { stage }\end{array}$ & Aim & Questions \\
\hline Opening & Presentation of participants & $\begin{array}{l}\text { First name, age, how long suffering from cervical } \\
\text { dysplasia and when they had undergone cone biopsy }\end{array}$ \\
\hline $\begin{array}{l}\text { Introductory } \\
\text { questions }\end{array}$ & $\begin{array}{l}\text { The participants' perception } \\
\text { of cervical dysplasia }\end{array}$ & $\begin{array}{l}\text { 1. Before going on to your personal experiences with } \\
\text { cervical dysplasia, please describe your views on this disease } \\
\text { Cues: precursor or disease in itself, prevalence, consequences, } \\
\text { cause, treatment options, time to cure } \\
\text { If woman knows about human papillomavirus: } \\
\text { 2. When did you get the information? } \\
\text { 3. Did it influence your views on cervical dysplasia? } \\
\text { 4. Overall, do you feel you have been well informed about cervical dysplasia? }\end{array}$ \\
\hline $\begin{array}{l}\text { Transitional } \\
\text { questions }\end{array}$ & $\begin{array}{l}\text { The participants' experiences } \\
\text { with the period up to conisation }\end{array}$ & $\begin{array}{l}\text { 5. How did you react when you heard that you had cervical dysplasia? } \\
\text { 6. Can you describe the period prior to conisation? } \\
\text { 7. How did you react to being told that you needed conisation? }\end{array}$ \\
\hline Key questions & $\begin{array}{l}\text { The effect of cervical dysplasia on } \\
\text { their quality of life after conisation }\end{array}$ & $\begin{array}{l}\text { 8. What are your main thoughts on the disease today? } \\
\text { Cues: change in perception of cervical dysplasia, termination of or stage in } \\
\text { the course of disease, future medical supervision, worries about the future } \\
\text { 9. Do you feel any physical symptoms or effects from having had cervical dysplasia? } \\
\text { 10. Does the dysplasia still affect you psychologically? If yes, how? } \\
\text { Cues: frame of mind (fear, shame, guilt, anger, depression), perception of self } \\
\text { and body, thoughts on the meaning of life, regrets (previous non-attendance } \\
\text { at cervical smear testing), worries about the future, disease phobia? } \\
\text { 11. Has cervical dysplasia affected your social life? If yes, how? } \\
\text { Cues: level of support, taboos, concerns about stigma } \\
\text { 12. Has the dysplasia affected your love life? If yes, how? } \\
\text { Cues: worries about infidelity, being contagious, conflicts with } \\
\text { and support from partner, disrupted sex life, fear of rejection } \\
\text { 13. Has there been a change in the way in which cervical dysplasia } \\
\text { affects you today compared with when you were diagnosed? }\end{array}$ \\
\hline $\begin{array}{l}\text { Closing } \\
\text { questions }\end{array}$ & & $\begin{array}{l}\text { 14. In conclusion, how do you assess the communication you had } \\
\text { with medical practitioners throughout the course of the disease? } \\
\text { 15. Is there anything you think we ought to have discussed but did not? }\end{array}$ \\
\hline
\end{tabular}

The other interview guides were similar and are available from GLM

The quotes cited below were selected as they illustrate some of the participants' most important experiences associated with being diagnosed with cervical dysplasia.

Initial reaction to diagnosis of cervical dysplasia

Most of the participants had reacted with shock, panic or tears when they received the first abnormal smear test result; they said it was like receiving a diagnosis of cancer. Although most of the women knew that this was not the case, fear and shock made it difficult for them to understand the explanations provided by the doctor. Many women were quite unprepared for an abnormal result because they had considered the test simply as a routine check-up.

He [the doctor] sat there with my medical record and said: "Well, I see that you have moderate or severe cervical dysplasia”. What?! My jaw dropped, my eyes and ears stopped working. I could hardly listen because of the pounding in my head: "Does this mean I will have cervical cancer soon? Can I have children? Can I do this? Can I do that? Am I really that sick? Although I see nothing on the outside, it's all wrong on the inside. I can't believe I hadn't noticed anything." It was really disturbing. It means you can actually walk around and develop cancer without knowing it, right? (Woman who had undergone conisation describing her reaction to receiving the results of her first colposcopy).

Even when the initial panic faded, concerns about the evolution of the cervical dysplasia typically persisted. The women continued to fear for their lives and their fertility and worried about how much treatment they 
would have to have and for how long they would need medical supervision.

Discrepancy between severity of dysplasia and level of anxiety experienced

Our findings suggest that the severity of cervical dysplasia diagnosed did not correspond to the level of anxiety experienced; in fact some women with low-grade lesions (mild dysplasia) who had not been conised appeared to be more anxious than women who had had higher-grade lesions (moderate or severe dysplasia) and had been conised. The difference in anxiety level between these women seemed to correspond to the level of their knowledge about cervical dysplasia and how long they had been under medical supervision.

When diagnosed with a low-grade lesion (mild dysplasia), the women said that they had not received much information about their condition. At this stage, the women said the follow-up period was extremely wearing and full of uncertainty; the longer the period of monitoring, the worse they felt. The unknown duration of follow-up and the possibility that the dysplasia would become more severe were worrying. Most of the women currently in this stage felt that their lives were 'on stand-by' and they described themselves as being sad, irritable and anxious. The concerns were particularly acute before new tests and when they were waiting for test results, since these events were important milestones. Many feared that their condition was constantly progressing and this considerably increased their need for explanations and action. At the stage of mild dysplasia, most of the women did not understand the meaning of the test results or the justification for the intervals between check-ups. Some thought that the intervals between check-ups were due to the problem of waiting lists in the health care system. Three women had asked for conisation simply to put an end to the waiting because they thought the longer they waited the higher the risk of the condition 'spreading'.

Several times, I experienced a kind of spontaneous fear of death. All of a sudden, it was like getting a bucket of cold water in the face. I'd cry and be sure that it would never turn out well. At the same time, I felt ashamed or guilty of making such a fuss about it because I wasn't really sick. I found that really, really difficult [...]. It was a great relief [when I was referred for conisation] because at that point, I'd been going to the hospital for nearly 1 1/2 years. At that stage, my life was being measured by: 'When am I going to the hospital again?' Those 2 1/2 to 3 months in-between check-ups... A few days before, I'd be really, really upset and be thinking that it was just terrible. Then I'd go, and afterwards I walked around feeling pain and bleeding for a few days and then I had to wait 2 weeks to get the test result. I'd be nervous about what I'd be told. [...] then it was only 1 1/2 2 months until I had to go back again. All the time, I felt that I was counting down to when it was time to go back. When more than a year had passed, I became so upset when I was at the hospital that the doctor said that when I called the next time to get the result, I could ask the chief consultant about undergoing conisation before the development of severe dysplasia. And so I did, and he just laughed at me and said that it was the most stupid thing he had ever heard. That I shouldn't make a big deal of it, because it wasn't like I was sick ... Obviously, I became extremely upset and I thought: "Well, it's probably just me that's being stupid". Then 3 months passed, I went back and it had progressed into severe dysplasia. At that point, I was like, if it can develop one stage in 3 months, I'll be damned if I want to wait very long for the operation! I was lucky to get a date for the surgery within 2 weeks. But I was like 'phew' [sighing] because they thought I was being ridiculous because I wanted the operation before it got to that stage, because I just couldn't take it anymore. It was too hard ... It really had a negative impact on my quality of life. (Woman who had undergone conisation).

\section{Reassuring effect of treatment and more information}

Five of the women who had undergone conisation had been through a long period of follow-up before the decision to operate was taken, and they were therefore able to provide insights into their experiences with earlier/milder stages of dysplasia. Where mild cervical dysplasia progressed to a higher-grade lesion, the necessity for conisation was upsetting but, at the same time, many women felt relief that something was finally being done. The three women who had been referred for colposcopy and conisation shortly after the initial smear test result had also been upset, but they were glad that they underwent the operation promptly (typically within 2 weeks) and that the time of uncertainty was short. The women who needed conisation were given more information about cervical dysplasia and the proposed treatment. This had a reassuring effect and most of these women thought of conisation as curative and the subsequent medical follow-up as a precautionary measure.

At the time of the interviews, most of the participants who had undergone conisation had received a negative test result after the 3-month post-conisation check-up. Many considered the next check-up at 6 months would be a milestone after which they hoped to be able to move on 
with their lives. For most, the diagnosis of their disease made them think about what was important in their lives. Some felt unsafe after having had a diagnosis of a potentially fatal disease that was not physically visible.

Effect of information on the mode of transmission of HPV and its role as the cause of cervical dysplasia

Women who did not know about HPV feared that they were now predisposed to developing cancer. For many women, the information provided before conisation included the role of HPV as the cause of cervical dysplasia. Learning about the sexual mode of transmission of HPV resulted in cervical cancer being seen as an unusual form of cancer. It brought about reflections about infection and re-infection, but it did not have adverse psychological effects or cause these women to see cervical dysplasia as stigmatising, unlike some other sexually transmitted diseases (McCaffery et al. 2004; Waller et al. 2005; McCaffery et al. 2006; Goffman 1968; Kahn et al. 2005, 2007; Maissi et al. 2004; Waller et al. 2007; Clarke et al. 1996; McCree and Dempsey 2005; Lee Mortensen and Larsen 2008). This was demonstrated by the fact that most of the participants had spoken openly about the disease not only with their closest friends and relatives, but also with colleagues and fellow students. These women viewed sex as a natural part of life and their perception of their disease was dominated by the issue of cancer, not that it was a sexually transmitted disease.

The role of communication with medical practitioners

The results from this study indicated that the women's concerns were dependent on the quality of communication with medical practitioners and the amount of information provided. The less the women knew about their condition, the more insecure and worried they felt.

My really sweet gynaecologist said to me: "It's not like you're dying, you know?" No, but it really takes up a lot of space in my life. I'm not sure that it would have made such a big difference if I had cancer. All the time, I felt there was so much uncertainty, uncertainty, uncertainty. I was headed toward something, but what was it? (Woman who had undergone conisation describing the period of waiting before the operation).

Many of the women felt there was a discrepancy between their own reaction of shock and fear and their GP's relatively carefree attitude when they learnt (sometimes over the telephone or from a secretary) about the first abnormal smear test result. The women felt the need for clear explanations about the difference between different stages of dysplasia and actual cancer. Vague expressions such as a 'precursor to cancer' or a 'precancerous lesion', for instance, was not perceived as being essentially different from cancer itself and tended to increase the women's anxiety.

The nurse put her hand on my stomach and said: “... it looks exactly as it should". All the muscles of my body relaxed and then she said: "...but I don't think we're all the way up there yet". Then the doctor inserts it a bit more and I could easily see [following the images on the monitor] that this tissue didn't look like the tissue we had just seen. And then the doctor went all quiet and I thought: "Well, say something, for God's sake!" It's at that point that she said: "Well, no, that does not look good at all". I just felt like crying, because I could see for myself that it did look really bad. Then they took the biopsies... And then she said: "If it's as bad as it seems, I'll call you within 10 days." After that, you just go around in a panic, looking at your phone to see if someone has called, and if it rings you think: "Is it her?" Because that means it's bad, right? (Woman who had not yet received results from a colposcopy).

The participants said they would have liked more compassion and better verbal and printed information about cervical dysplasia at the time of diagnosis. Regardless of the stage of dysplasia, they wanted to know about the medical rationale for the intervals between check-ups, the meaning of the test results, the possible consequences for fertility and about HPV as the causal factor. Retrospectively, the women who had undergone conisation felt that their anxiety during the course of disease had been significantly worsened by poor communication with the various doctors and nurses. Some participants suggested that young women in general should be better informed about cervical dysplasia and that more women would participate in screening programmes if they knew about the prevalence of HPV and the association of HPV with cervical cancer. They also felt that GPs should encourage Pap smear testing when performing other gynaecological examinations, for instance.

\section{Discussion}

The present study is, to our knowledge, the first of its kind to assess and compare the experiences of young Danish women diagnosed, via routine cytological screening, with cervical dysplasia of varying grades of severity. The use of qualitative research methods has produced an in-depth account of how these young women react to and deal with the diagnosis and management of this disease. The results suggest that patients' perceptions of cervical dysplasia 
significantly differ from those of medical professionals and that women's concerns are not aggravated in proportion to the severity of the cervical dysplasia.

Our results show that the detection of cervical abnormalities, whatever their severity, leads to significant distress and anxiety. As other studies have also shown, many women are quite unprepared for the first abnormal result because they had considered the test as a routine check-up (French et al. 2006; Hounsgaard 2004). The participants in our study were grouped according to whether they had or had not undergone conisation. The results revealed, contrary to what might be expected, that women diagnosed with lower-grade lesions and who had not been conised were more likely to experience anxiety and stress due to their disease, since they lacked information about their condition and the period of follow-up with regular checkups, before treatment is initiated or before regression of the lesion is confirmed, can be long. From a medical viewpoint, watchful waiting is a means of avoiding unnecessary invasive treatment. From the women's viewpoint, their lives during this period of watchful waiting are full of apprehension, waiting for check-ups and the subsequent results and the fear that the lesion will probably 'spread' or develop into cancer. The women diagnosed with lowergrade lesions, in particular, had poor understanding of their condition, its cause and the medical rationale for the followup and treatment provided. Their anxiety was linked to inadequate communication with medical professionals (Bunge et al. 2009). This is in line with other studies showing that women often have poor understanding of the meaning of cervical smear test results (Lauver et al. 1999; French et al. 2004, 2006; Lerman et al. 1991; Ideström et al. 2003; Neale et al. 2003; Campion et al. 1988; McCaffery et al. 2004; Fleurence et al. 2007; Hounsgaard 2004; Maissi et al. 2004).

In this study, women with higher-grade lesions reported less disease-related anxiety after conisation. To some, the period of uncertainty had been shorter as prompt treatment (conisation) was given, but most importantly, before conisation they had received more information about the causes and clinical management of cervical dysplasia, which reassured them. Results from other studies have also suggested that anxiety related to cervical dysplasia is closely related to lack of knowledge (Lauver et al. 1999; French et al. 2004, 2006; Lerman et al. 1991; Ideström et al. 2003; Neale et al. 2003; Campion et al. 1988; McCaffery et al. 2004; Fleurence et al. 2007; Hounsgaard 2004).

Although we cannot exclude negative selection bias, i.e. an over-representation of women with negative experiences who are more likely to accept to participate, the results from this study do not suggest that there was any. We know that focus group methodology has the risk that unusual experiences are under-reported and negative experiences are over-reported (Halkier 2003). In this study, the focus group participants did not restrain themselves from expressing singular perceptions. Moreover, participants were given the opportunity to express themselves freely, without peer group pressure, in the individual interviews (Bech Risør et al. 2005; Kvale 1996; Spradley 1979).

This study was based on qualitative methodology and thus included a relatively small number of participants. Many of our results agree with those of previous studies and we do not consider that more interviews would have produced more qualitative knowledge from women targeted by this study. However, it would be interesting to examine the experiences of women who have been monitored for a longer post-operative period. The women in this study who had undergone conisation said they imagined that a negative test result for the 6-month check-up after conisation would indicate cure and thus they could 'start again'. We did not include women who had had the results from this check-up, so we cannot say if they would really have felt that way. Results from other studies do not provide clear-cut answers to whether the psychological effects of having cervical dysplasia are short-term or of longer duration (Lerman et al. 1991; Ideström et al. 2003; Hounsgaard 2004). Further studies should also investigate the experiences of older women and those of women from ethnic minorities and explore the effect of factors such as knowledge of the sexual transmission of HPV on their perception of disease.

Knowing that HPV is the cause of cervical dysplasia did not seem to increase the worries of these young Danish women or lead to feelings of stigma. Some previous studies have suggested that knowing about the sexual transmission of HPV can lead to feelings of empowerment and improve health-related behaviour, for example, by encouraging condom use and participation in screening programmes for cervical cancer (Kahn et al. 2005). On the other hand, others have suggested that this knowledge can lead to women seeing cervical dysplasia as stigmatising (Waller et al. 2005; McCaffery et al. 2006; Kahn et al. 2005, 2007; Maissi et al. 2004; Waller et al. 2007; Clarke et al. 1996; McCree and Dempsey 2005) and this may act as a barrier to improved health-related behaviour (Waller et al. 2007). We cannot exclude that some women may have not accepted to participate in the present study because of this negative perception. Perception of disease is highly dependent on socio-cultural context (Kleinman 1988; Hahn 1984; Berger and Luckmann 1987) and the young Danish women in our study seemed to have associated cervical dysplasia with cancer rather than with a sexually transmitted disease.

In Denmark, HPV vaccination has been included in the childhood immunisation programme and, therefore, has been free of charge since January 2009 for girls aged 12 and for 13- to 15-year-old girls in an initial catch-up 
programme. Provided that women's participation in the cervical screening programme remains unchanged, vaccination is expected to prevent approximately $70 \%$ of cervical cancer cases, i.e. those caused by HPV 16 or HPV 18 (Bosch and Lorincz 2002; Trottier and Franco 2006; Smith et al. 2007). Our study suggests that the heavy psychological burden experienced by women who are diagnosed with cervical dysplasia during cervical screening could also be greatly reduced by vaccination.

Our study has shown that it is important to address women's fear of cancer and need for information about cervical dysplasia from the moment of diagnosis, regardless of the stage of the lesion. Improved communication may reduce the divergence between patients' and practitioners' perceptions of cervical dysplasia so that women may understand the medical viewpoint of watchful waiting as a reassuring means of monitoring the disease and avoiding unnecessary treatment, rather than as a distressing delay. Vaccinated women also need to understand that the vaccine cannot prevent all cervical cancers and that it will still be necessary to attend screening. With the proper communication about HPV being an extremely prevalent virus that will infect almost everybody during their lifetime (National Board of Health 2007b), there is a possibility of promoting health care behaviour regarding the uptake of HPV vaccination as well as participation in screening programmes for cervical cancer.

\begin{abstract}
Acknowledgements This paper was originally published in Danish (Lee Mortensen and Adeler 2009). GLM translated the paper into English. The authors would like to thank Margaret Haugh and Heidi Mattock for editorial assistance as well as Marie Bjørnager Jensen for her assistance with the focus group interviews and Steen Lee Mortensen for discussing all methodological and analytical steps of the study and critically revising the original manuscript. We also wish to thank Lone Kjeld Petersen (medical chief at the Gynaecology and Obstetrics ward at Skejby Hospital, Aarhus), Morten Ring (specialist in gynaecology and obstetrics, Aalborg), and Helle Field (GP in Aarhus) for their invaluable assistance in recruiting the participants in the study.
\end{abstract}

Conflict of interest GLM received an unrestricted research grant from Sanofi Pasteur MSD for this study. ALA has no conflict of interest.

Authors' contributions GLM conceived the study and its design, carried out data collection, analysed and interpreted the data and drafted and translated the manuscript. ALA participated in the inclusion of patients, drafted the medical parts of the manuscript and revised the manuscript critically for important intellectual content. Both authors read and approved the final manuscript.

Open Access This article is distributed under the terms of the Creative Commons Attribution Noncommercial License which permits any noncommercial use, distribution, and reproduction in any medium, provided the original author(s) and source are credited.

\section{References}

Bech Risør M, Mogensen H, Paarup B et al (2005) Narrativer [Narratives]. Tidsskrift for Forskning i Sygdom og Samfund;2

Berger P, Luckmann T (1987) The social construction of reality. Penguin Books, Harmondsworth

Bishop GB (1991) Understanding the understanding of illness: lay disease representations. In: Skelton JA, Croyle RT (eds) Mental representation in health and illness. Springer, New York, pp 32-59

Bjerregaard B (2007) Sundhedsstyrelsens nye anbefalinger for screening for livmoderhalskræft. [New recommendations of cervical cancer screening from the National Health Board]. Månedsskr Prakt Lægegern 85:1391-1401

Bosch FX, Lorincz A, Muñoz N et al (2002) The causal relation between human papillomavirus and cervical cancer. J Clin Pathol 55:244-265

Bro F, Svanholm H, Stovring H, Frandsen C (2008) Utilsigtede hændelser $\mathrm{i}$ et vaginalcytologisk screeningsprogram [Adverse incidents in a cervical cancer screening programme]. Ugeskr Laeger 170:2794-2797

Bunge M, Mühlhäuser I, Steckelberg A (2009) What constitutes evidence-based patient information? Overview of discussed criteria. Patient Educ Couns: doi:10.1016/j.pec.2009.10.029

Campion MJ, Brown JR, McCance DJ et al (1988) Psychosexual trauma of an abnormal cervical smear. Br J Obstet Gynaecol 95:175-181

Clarke P, Ebel C, Catotti DN et al (1996) The psychosocial impact of human papillomavirus infection: implications for health care providers. Int J STD AIDS 7:197-200

Clemmensen IH, Nedergaard KH, Storm HH (2006) Kræft i Danmarken opslagsbog [Cancer in Denmark - a work of reference]. http:// www.cancer.dk/Cancer/soeg.htm? resetsearch=true\&q=kræft i danmark. Accessed 20 Nov 2009

Danish Gynaecological Cancer (2007) Retningslinier for visitation, diagnostik, behandling og kontrol af cervix cancer [Guidelines for testing, diagnosis, handling and treatment of cervical cancer] http://dgc.eu.com/fundanemt/files/filer/DGC_retningslinier_for_ cervix_revideret20jan2007.pdf

Engholm G, Ferlay J, Christensen N et al (2008) NORDCAN: cancer incidence, mortality and prevalence in the Nordic countries, Version 3.2. Association of Nordic Cancer Registries. Danish Cancer Society. Available via http://www.ancr.nu. Accessed July 2009

Ferlay J, Bray F, Pisani P, Parkin DM (2004) GLOBOCAN 2002: cancer incidence, mortality and prevalence worldwide. IARC CancerBase no. 5, version 2.0. IARC Press, Lyon. http://wwwdep.iarc.fr/globocan/methods.htm. Accessed 13 Apr 2007

Fleurence RL, Dixon JM, Milanova TF, Beusterien KM (2007) Review of the economic and quality-of-life burden of cervical human papillomavirus disease. Am J Obstet Gynecol 196:206-212

French DP, Maissi E, Marteau TM (2004) Psychological costs of inadequate cervical smear test results. Br J Cancer 91:18871892

French DP, Maissi E, Marteau TM (2006) The psychological costs of inadequate cervical smear test results: three-month follow-up. Psychooncology 15:498-508

Goffman E (1968) Stigma. Notes on the management of spoiled identity. Penguin Books, Harmondsworth

Hahn RA (1984) Rethinking "illness" and "disease". Contrib Asian Stud 18:1-23

Halkier B (2003) Fokusgrupper [Focus groups]. Roskilde University Press, Roskilde

Hounsgaard L (2004) Potentiel sygdom sætter spor [Potential disease leaving its traces]. PhD thesis, Department of Health Sciences, Aarhus University

Ideström M, Milsom I, Andersson-Ellström A (2003) Women's experience of coping with a positive Pap smear: a register- 
based study of women with two consecutive Pap smears reported as CIN 1. Acta Obstet Gynecol Scand 82:756-761

Kahn JA, Slap SGB, Bernstein DI et al (2005) Psychological, behavioral, and interpersonal impact of human papillomavirus and Pap test results. J Womens Health (Larchmt) 14:650-659

Kahn JA, Slap SGB, Bernstein DI et al (2007) Personal meaning of human papillomavirus and Pap test results in adolescent and young adult women. Health Psychol 26:192-200

Kleinman A (1988) The illness narratives. Suffering, healing, and the human condition. Basic Books, New York

Kvale S (1996) InterViews. An introduction to qualitative research interviewing. Sage Publications, Thousand Oaks

Lauver DR, Baggot A, Kruse K (1999) Women's experiences in coping with abnormal Papanicolaou results and follow-up colposcopy. J Obstet Gynecol Neonatal Nurs 28:283-290

Lee Mortensen G, Adeler AL (2009) Kvinders erfaringer med celleforandringer [Women's experiences with cell changes]. Ugeskr Laeger 171:1934-1938

Lee Mortensen G, Larsen HK (2008) Kondylompatienters livskvalitet [Quality of life of patients with condyloma]. Ugeskr Laeger 170:3858-386

Lerman C, Miller SM, Scarborough R et al (1991) Adverse psychologic consequences of positive cytologic cervical screening. Am J Obstet Gynecol 165:658-662

Maissi E, Marteau TM, Hankins M, Moss S, Legood R, Gray A (2004) Psychological impact of human papillomavirus testing in women with borderline or mildly dyskaryotic cervical smear test results: cross sectional questionnaire study. BMJ 328:1293

Malterud K (2004) Kvalitative metoder i medicinsk forskning [Qualitative methods in medical research]. University Press, Oslo

McCaffery K, Waller J, Forrest S et al (2004) Testing positive for human papillomavirus in routine cervical screening: examination of psychosocial impact. BJOG 111:1437-1443
McCaffery K, Waller J, Nazroo J et al (2006) Social and psychological impact of HPV testing in cervical screening: a qualitative study. Sex Transm Infect 82:169-174

McCree DH, Dempsey AF (2005) Psychological impact of human papillomavirus and Pap testing in adolescents and young women. J Womens Health (Larchmt) 14:742-744

National Board of Health (2007a) Anbefalinger for screening for livmoderhalskræft. [Recommendations regarding cervical cancer screening]. Copenhagen

National Board of Health (2007b) Reduction in the risk of cervical cancer by vaccination against human papillomavirus (HPV) - a health technology assessment, 9(1). Danish Centre for Health Technology Assessment, Copenhagen

Neale J, Pitts MK, Dunn PD, Hughes GM, Redman CW (2003) An observational study of precolposcopy education sessions: what do women want to know? Health Care Women Int $24: 468-475$

Smith JS, Lindsay L, Hoots B et al (2007) Human papillomavirus type distribution in invasive cervical cancer and high-grade cervical lesions: a meta-analysis update. Int J Cancer 121:621-632

Spradley JP (1979) The ethnographic interview. Holt, Rinehart and Winston, New York

Trottier H, Franco EL (2006) The epidemiology of genital human papillomavirus infection. Vaccine 24(Suppl 1):S1-S15

Waller J, McCaffery K, Nazroo J et al (2005) Making sense of information about HPV in cervical screening: a qualitative study. Br J Cancer 92:265-270

Waller J, Marlow LA, Wardle J (2007) The association between knowledge of HPV and feelings of stigma, shame and anxiety. Sex Transm Infect 83:155-159

Winther Jørgensen M, Phillips L (1999) Diskursanalyse som teori og metode [Discourse analysis as a theory and method]. Roskilde University Press, Roskilde 